\title{
Reflection: Snatched Commensality: \\ To eat or not to eat together in times of Covid-19 in France ${ }^{1}$.
}

\author{
Estelle Fourat $^{1}$, Tristan Fournier ${ }^{1}$, Olivier Lepiller ${ }^{2}$ \\ ${ }^{1}$ CNRS - Iris, EHESS, Paris (France) \\ ${ }^{2}$ CIRAD - MoISA, Univ. Montpellier (France)
}

\section{Corresponding author:}

Tristan Fournier

CNRS - Iris, Paris (France)

tristan.fournier@,ehess.fr

\begin{abstract}
During the Covid-19 pandemic, the French Government imposed a strict lockdown from March $17^{\text {th }}$ to May $11^{\text {th }} 2020$. These extraordinary times challenged the social norm of commensality, a practice that is particularly strong and engrained in France. How has lockdown impacted meal-sharing habits? How have the rules and norms of commensality withstood the weakening of social bonds caused by lockdown? Based on a qualitative study of 20 socially diverse households, this essay proposes a typology of adaptive commensal eating patterns: 1) Eating together can provide reassurance by reproducing ordinary routines or by enacting food traditions; 2) Tinkering with lockdown rules leads to creative new forms of commensality, or to an ersatz of commensality; 3) Sharing every meal with the same people can trigger the rejection of commensal practices. These patterns may also represent possible phases in the experience of lockdown, since some individuals shifted from one pattern to another. The final part of the paper discusses the very nature of the social link highlighted through the lens of commensality.
\end{abstract}

\footnotetext{
${ }^{1}$ Pre-print version of: Fourat E., Fournier T. \& Lepiller O. (2021) "Reflection: Snatched Commensality: To eat or not to eat together in times of Covid-19 in France”, Food \& Foodways, 29(2): 204-212.
} 


\section{Introduction}

From March $17^{\text {th }}$ to May $11^{\text {th }} 2020$ (a total of 56 days), the French Government issued a nationwide stay-at-home order, and closed schools, to prevent the spread of the Covid-19 virus. People required a certificate (printed off or downloaded onto their smartphone from the official Government website) to leave the house, and could only go out for the following reasons: commuting to and from work (if working from home was not possible); medical appointments; essential family duties such as caring for the elderly; or shopping for "essential" goods including food. For one hour a day, people were also permitted to walk their pet or exercise within a one-kilometer radius.

Overnight, social interactions became fixed and sparse: people living alone had to remain alone, and people living with others (in a family unit or shared household) had to remain together. How did this disruption of social relations affect commensality - traditionally defined as the practice of sharing food with people in the same location at the same time? Meals constitute a practical tool for building and maintaining social ties (Julier 2013) - especially so in France, where commensality is very marked in daily practices, particularly for lunch and dinner (Poulain 2002). Evidently, as in other European societies (Yates and Warde 2017; Mestdag and Glorieux 2009), several factors indicate - even before the pandemic - a progressive individualization of mealtimes: the time allotted to meals continues to decrease, while both eating out and takeout have become considerably more widespread. However, for French people, eating remains a strong and structuring social norm, a "social affair" (Fischler 2011) attachment to this norm leads the French to develop a less individualized relation to food than people in other countries (especially the United States), and thus to further devalue the practice of eating alone.

In this essay, we propose to explore how lockdown has affected the rules, and forms, of commensality in France. Thus, we aim to study how lockdown has impacted meal-sharing habits and, in turn, how the rules and norms of commensality have withstood the weakening of social bonds caused by lockdown. 


\section{A methodology adapted to lockdown}

We conducted a qualitative survey of 20 socially diverse French households, aimed at documenting their food practices over the entire duration of lockdown. Due to social distancing, the survey comprised an online questionnaire and a semi-structured phone interview. The participants were recruited from among our respective extended social networks, and to respect their privacy and anonymity each author only interviewed members of their co-authors' networks. The sample may be too small to draw general conclusions, but it does indicate some interesting trends.

On a practical level, we emailed out two requests for 24-hour recalls of food consumption on days 15 and 30 of lockdown. These featured open and multiple-choice questions on: the circumstances in which food was consumed; involvement in food chores; the quantities of food and drink consumed; and food provisioning. During the final week of lockdown (the end date having been announced by the French Government), we additionally investigated the experience of lockdown before it ended, via a phone interview in which participants discussed: a) the material, social and psychological experience of lockdown, and b) the "food experience" during lockdown (supply, culinary practices, meal organization, commensality).

To compose our sample $(n=20)$, we selected half of the participants from urban locations and the other half from rural settings, assuming that the latter may have a different experience of lockdown due to the proximity of nature and the likelihood of having a garden. We were also careful to select participants with diverse professional statuses: unemployed, student, retired, manager, worker, etc. The sample was composed of 13 women and 7 men, ranging in age from 23 to 90 and living in different types of social configurations: alone $(n=4)$, with a partner $(n=4)$, in a single-parent family $(n=3)$, in a nuclear family $(n=5)$ and with housemates ${ }^{2}(n=4)$. Ethnicity was not requested, in compliance with French survey protocols, nor was religion.

\section{Three patterns of commensal eating during lockdown}

By analyzing these data, we have been able to construct a typology identifying three patterns of commensal practices during lockdown. Each of these is broken down into subpatterns.

\footnotetext{
2 Pre-existing flat-sharing, or house shares created for lockdown.
} 


\section{1) Reproducing normative meals: Commensality as reassurance}

In a very uncertain environment, amid destructured routines and possibly fear of the disease, this pattern embodies the practice of reproducing normative shared meals as reassurance that something remains unchanged.

Mimicking the ordinary. Our first observation was that meals act to punctuate a disrupted daily life. Eating together normalizes the abnormal and helps people find meaning in an unusual situation. A couple of foodies we interviewed live in the countryside, in a stone cottage which they own. He is a market gardener; she is a freelance writer. The couple were expecting a baby, who was born during lockdown. For them, the period was literally a moment of withdrawal and sharing activities around food. On the subject of meals, the man explained: "It was our little daily get-together. We'd cook meals, then sit down to eat, spending an hour together. That was our shared moment. [...] For her [his partner's] birthday, I invited her for a meal at our home restaurant." Mealtimes can thus become even more elaborate (i.e. recreating the restaurant experience at home for his partner's birthday), in order to produce a celebratory commensal experience to help soothe the anxiety-provoking experience of lockdown. These two dimensions (normality/festivity) resurface in another interview. A 44-year-old man, a consultant living with his partner in a small apartment in the center of a big city, explained how much meals mattered amid disrupted daily life. His partner, who lost her job at the beginning of lockdown, started to cook new recipes in an effort to add a little escapism to their gloomy routine (before lockdown, they had been frequent restaurant goers, and regularly went out with friends): "Even though it's been a difficult time, especially for her, there was a certain joy in opening the cookbook, choosing a recipe, preparing it, then sampling each new dish together."

In the name of tradition. Leading a normal life was considered so important and necessary that some people upheld tradition by continuing to invite neighbors over on special occasions - as though it were the obvious thing to do, and with no concern for disobeying lockdown rules. One man (a 50-year-old small business owner) and his family invited neighbors and their children round for Easter, hiding chocolate eggs in the garden for the children and enjoying an aperitif (a pre-dinner drink with nibbles) with the parents: "That was the only time we had people over, it was a wonderful occasion!’. This example illustrates how individuals reproduced, almost automatically, a festive tradition involving conviviality around food. In this example, there was no specific hygiene protocol, as the imperative was for life to feel normal. 
Thus, the normative nature of the commensal experience led people to suspend, within clearly defined commensal situations, the lockdown rules they were fully accepting otherwise. In so doing, they were acting in accordance with a taken-for-granted form of normality.

\section{2) Tinkering with the rules: New forms of commensality}

This pattern concerns the practice of reproducing normative shared meals in different, creative forms to tinker with French public health recommendations. We saw this among particularly self-reflexive people who developed personal ways of adapting the rules. Having been used to eating together, and setting great store by it, they fully intended to continue - even with people who did not belong to their household.

Covid-secure commensality. We observed people having knowingly established protocols to preserve, and sometimes even create, commensal situations. A typical illustration was a family of two adults and two children, living in a comfortable apartment in Paris. Though totally sealed off from the outside world, for the first time they began using their small backyard, where they shared aperitifs - and even meals - with neighbors they had never met before. Lockdown thus became an occasion to expand their social network through food, in a way they deemed safe. Sometimes, the elaborate hygiene protocol was more rigorous. This was the case, for instance, with one woman (a 30 year-old public service executive), who was living alone in a big city. As someone used to eating out with friends, she was really struggling to handle the solitude. So, jumping on the opportunity to share a veg box with a neighbor, the pair quickly decided to prolong the feeling of togetherness over dinner. They set up a comprehensive hygiene protocol to maintain this commensality at a worthwhile cost/benefit ratio: she washed her hands on arrival at his house, dried them with her own towel (which she left there for the duration of lockdown), and took her own cutlery, before sharing food they had each cooked in their respective homes. They accepted the risk because it was, according to them, "worth it": "The loneliness would have done us more harm than the risk of getting the virus. It might not have been smart, but I don't know how we'd have coped otherwise."

Remote commensality. Maintaining social ties was facilitated by technology, which made it possible to simulate the experience of eating or drinking together - at the same time and face to face, but in different places - via a screen. One man (a 48-year-old public service employee), living alone in the suburb of a small town, organized very frequent online aperitifs with his 
friends, having been used to meeting them several times a week in a restaurant. "I have friends I've known for years and years. We meet up, have a drink, and eat together. [...] So, every weekend, on Friday, Saturday and Sunday evenings, we have these little video calls together. It's a nightly ritual". As people were physically apart, there was no need for hygiene protocols, and no risks involved. However, the benefit was only partial because the interactions were, in his words, impoverished compared to "real life". As a result, he and his friends never made it to the next stage: a virtual dinner. "A meal would be too complicated. Some of them have children, so it would require too much organization. It's just about seeing each other, and having a chat and a drink. We'll save the meals for real life!"

An ersatz of commensality. Although eating together was not possible, we observed that circulating food items, or pictures of food, enabled people to share food in a way akin to a reallife commensal situation. For one older woman (officially retired, although still working to earn extra money), whose social interactions had decreased over lockdown, a virtual bond with her family became more necessary than ever. Gradually, she began sharing pictures of food with her children, resulting in the creation of a WhatsApp group where they shared recipes and photos of dishes made with seasonal fruits (acacia flower fritters, elderflower cordials, strawberries and cream, etc.). At the start of lockdown, she could barely stomach anything, but she reported having regained her appetite through this process. Another remarkable example is that of a man (a 40-year-old bank employee) living in the heart of one of France's largest cities, who was unable to celebrate Ramadan in his usual way. "Really, you could say that lockdown is an advantage when it comes to observing Ramadan. Usually, I'm constantly tempted by what my colleagues are eating, and I miss the daily café visits with my brother. But with lockdown it's easier, because these temptations no longer exist. However, Ramadan is also a spiritual and celebratory period, and we can't celebrate that side of it any more. We can't go to the mosque, participate in group prayers, or meet in the evening to eat with family and friends." Nevertheless, he adapted to the unusual situation by creating a remote commensal experience with his mother, in the form of cakes which she baked and had sent to him via his brother.

\section{3) Getting overwhelmed: The flip side of commensality}

Being locked down as a couple, with family, or with roommates can lead to daily tensions around food. Lots of people spontaneously reported fantasizing about spending time alone and eating alone. People who spent lockdown with others often experienced a peak in tensions, 
followed by a rift and new, more individualized eating arrangements. We identified two subpatterns triggered by "forced" commensality.

Social facilitation to overindulge. The first subpattern relates to carnivalesque commensal practices, which could lead to health risks, due to social facilitation - i.e. the fact that being in company can incite people to consume more food and drink, notably alcohol (Sobal 2000; Fournier 2012). These behaviors of forced commensality were especially pronounced during the first weeks of lockdown, then subsequently decreased. One man (a craftsman in his thirties, living in a house share of 18 people in the countryside), explained that he and his housemates gradually began drinking much more alcohol than usual - ultimately too much, in his view. "We never had much booze in the house before because it's not included in the collective budget, so we set up a common pot to fund it and started drinking on a regular basis. It was a bit like being on vacation! But I realized we couldn't keep drinking like that. I was drinking every day and that bothered me. And it also becomes expensive".

An overdose of commensality. The second subpattern encompasses attempts to reconfigure social ties which broke down due to excessive contact with others, resulting in an overdose of commensality. A women in her twenties (a project manager for a Parisian company with around thirty employees), who spent lockdown with her boyfriend and four other close friends in a family house in the countryside, recounted how oppressive forced commensality can become over time: "At first, we thought we didn't have to eat together all the time. If anyone wanted to eat on their own, they could. But when it came to it, I didn't feel able to - I think it really excludes you, and it's not ideal for the group". Ultimately, they ended up eating every meal together. She would have liked to eat alone with her boyfriend on occasion, but didn't dare depart from the tacit rule of commensality lest she cause a rift. Conversely, a 39-year-old mother (living in a large house in Toulouse with her partner and their three children), who usually loves to cook the family dinners, became progressively overwhelmed by the tensions provoked by lockdown ${ }^{3}$. Planning and organizing three meals a day for five people - while working from home - took a considerable physical and mental toll, to the point where the dinner table gradually became the place for settling scores. Accusations levied at the children mainly focused on the help they were failing to provide spontaneously (setting the table, clearing the

\footnotetext{
3 The lockdown increased gender inequalities over home cooking, which are already widely documented under normal circumstances. $25 \%$ of French women living in heterosexual couples stated that they were spending more time preparing meals during lockdown (IFOP 2020).
} 
dishes, etc.). After three weeks, they stopped eating breakfast and dinner together. They literally abandoned commensality: "When it came to evening meals, no one had much appetite - at least, not at the same time. At first, I found it hard because I really care about the mealtimes where we all come together, and that was basically no longer the case. It was a case of 'no, I'm not hungry', or 'no, I'm not coming, I'll come later'. From that point on, I started to say to myself 'come on, just leave it'. So now we put out the serving dishes, they [the children] help themselves, and then do as they please." The burden of being together all the time and eating every meal within the same household unit led people to reject commensality and to seek spaces of freedom.

\section{Conclusion: Commensality and the plasticity of the social link}

By studying how commensality was reconfigured during the first French Covid-19 lockdown in the spring of 2020, we have highlighted how people were able to reconstruct the social link under constraints. These constraints (the obligation to stay at home other than for "essential" activities, social distancing requirements, etc.) suppressed or considerably reduced what Sobal (2000) calls commensal circles (networks of people whom an individual is likely to eat with), while commensal units (the individuals eating together at a given meal) shrunk to the domestic group. This study allowed us to emphasize three main observations, possibly corresponding to three stages of the lockdown commensality experience: 1) the strength of the commensality norm that some people felt almost obliged to perform, despite lockdown constraints, and while generally observing lockdown rules; 2) the creativity of those who tinkered and used "tricks" 4 (de Certeau et al. 1998), sometimes involving virtual devices, to negotiate these constraints or bend lockdown rules; 3 ) the narrowing of commensal circles to the domestic commensal unit, which can prove oppressive and may lead the commensal link to break down.

Beyond commensality, this latter observation invites discussion of the very nature of the social link. Indeed, it is often assumed that rituals, such as those at issue in commensality, aim at lubricating the social relations, while ensuring their predictability. In tandem, our study underlines another key aspect of the social link: its plasticity. Not only because the social link is plastic and adaptable, but also because it has to be plastic to keep its elasticity and continue to be effective. This plasticity is nourished by participation in a variety of more or less

\footnotetext{
${ }^{4}$ Comprising micro-resistances that constitute spaces of creativity and freedom, as well as possibilities for emancipation.
} 
controlled and predictable commensal situations (involving various commensals, places, times, etc.). But at the time of writing, bars and restaurants are still closed and an overnight curfew after $6 \mathrm{pm}$ is in place. Outside-the-home and public commensal situations are largely outlawed, reducing a discussion space where people can present different views and build common ones. Commensal eating binds the commensals as much as it keeps away those who are not part of the shared meal (Grignon 2001): if this context were to endure, what might the implications be for the social link in the long run? In our opinion, the increasing complexity of commensal rules due to restrictions and the fear of contamination will produce two opposite social behaviours: on the one hand, a withdrawal into oneself resulting in the rarefaction of commensal occasions, and on the other hand, resistance from people resulting in adaptative commensal situations (guests sleeping at home after evening meals, clandestine restaurants, etc.).

\section{Acknowledgments}

Our thanks to all the respondents, and to Lucy Ackroyd and Cadenza Academic Translations for editing this paper.

\section{References}

Certeau, Michel de, Luce Giard, and Pierre Mayol. 1998. The Practice of Everyday Life, Vol. 2: Living and Cooking. Translated from the French by Timothy J. Tomasik. Minneapolis: University of Minnesota Press.

Fischler, Claude. 2011. "Commensality, Society and Culture”. Social Science Information 50, nos. 3-4: 528-48.

Fournier, Tristan. 2012. "Suivre ou s'écarter de la prescription diététique. Les effets du 'manger ensemble' et du 'vivre ensemble' chez des personnes hypercholestérolémiques en France". Sciences Sociales et Santé 30, no. 2: 35-60.

Grignon, Claude. 2001. "Commensality and Social Morphology: An Essay of Typology". In Food, Drink and Identity: Cooking, Eating and Drinking in Europe Since the Middle Ages, edited by Peter Scholliers, 23-33 Oxford: Berg Publishers.

IFOP. 2020. Quel est l'impact du confinement sur le poids et les habitudes alimentaires des Français ? Paris: IFOP. https://www.ifop.com/wpcontent/uploads/2020/05/analyse Ifop Darwin FK 2020 05.06.pdf.

Julier, Alice P. 2013. Eating Together: Food, Friendship and Inequality. Urbana: University of Illinois Press.

Mestdag, Inge, and Ignace Glorieux. 2009. "Change and Stability in Commensality Patterns: A Comparative Analysis of Belgian Time-Use Data from 1966, 1999 and 2004". The Sociological Review 57, no. 4: 703-26.

Poulain, Jean-Pierre. 2002. "The Contemporary Diet in France: 'De-structuration' or From Commensalism to "Vagabond Feeding'". Appetite 39, no. 1: 43-55.

Sobal, Jeffery. 2000. "Sociability and Meals: Facilitation, Commensality, and Interaction". In Dimensions of the Meal: The Science, Culture, Business, and Art of Eating, edited by Herbert L. Meiselman, 119-33. Gaithersburg: Aspen Publishers. 
Yates, Luke, and Alan Warde. 2017. "Eating Together and Eating Alone: Meal Arrangements in British Households". The British Journal of Sociology 68, no. 1: 97-118. 